\title{
Prevalence of horizontal alveolar changes in edentulous patients: a retrospective tomographic study
}

\author{
Márcio Américo Dias ${ }^{(a)}$ \\ Giuseppe Romito(b) (D) \\ Cristina Cunha Villar ${ }^{(b)}$ (iD \\ Vitor Marques Sapata(b) (D) \\ Marcelo Lucchesi Teixeira ${ }^{(c)}$ (iD \\ Antonio Carlos Aloise (d) (D) \\ Carolina Mannina(a) (D) \\ Luís Guilherme Scavone de Macedo(d) \\ Peter Karyen Moy(e) (iD \\ André Antonio Pelegrine ${ }^{(d)}$ (iD \\ (a) São Leopoldo Mandic Institute, Faculdade \\ São Leopoldo Mandic, Campinas, SP, Brazil. \\ (b) Universidade de São Paulo - USP, Dental \\ School, Department of Stomatology, São \\ Paulo, SP, Brazil. \\ (c)São Leopoldo Mandic Institute, Faculdade \\ São Leopoldo Mandic, Department of \\ Prosthodontics, Campinas, SP, Brazil. \\ (d) São Leopoldo Mandic Institute, Faculdade \\ São Leopoldo Mandic, Department of \\ Implant Dentistry, Campinas, SP, Brazil. \\ (e) $\cup C L A$, Department of Oral \& Maxillofacial \\ Surgery, Los Angeles, CA, USA.
}

Declaration of Interests: The authors certify that they have no commercial or associative interest that represents a conflict of interest in connection with the manuscript.

Corresponding Author:

André Antonio Pelegrine

E-mail: pelegrineandre@gmail.com

https://doi.org/10.1590/1807-3107bor-2020.vol34.0016

Submitted: August 13, 2019

Accepted for publication: December 10, 2019

Last revision: January 17, 2020
Abstract: Horizontal bone loss after tooth extraction is a common finding that demands bone reconstruction in various cases. The aim of this study was to assess the horizontal alveolar status in partially and completely edentulous patients using cone-beam computed tomography (CBCT). In total, 1516 CBCT scans of 1404 adult patients were analyzed. Assessment of the images was performed in accordance with the previously published horizontal alveolar change (HAC) classification, which categorizes horizontal bone defects into four classes: HAC 1, HAC 2, HAC 3 and HAC 4 (from the least severe to the most severe condition). Analysis of 1048 scans from partially edentulous patients presented a distribution of $63.55 \%, 22.14 \%, 13.36 \%$ and $0.95 \%$ in HAC 1, HAC 2, HAC 3 and HAC 4, respectively. Analysis of 468 scans from completely edentulous patient images presented a distribution of 19.87\%, 28.63\%, 41.67\% and 9.83\% in HAC 1, HAC 2, HAC 3 and HAC 4, respectively. Based on these results, as in HAC 4, no cancellous bone was found between the cortical buccal and lingual/palatal bone plates, it seems reasonable to state that the absence of cancellous bone is higher in completely edentulous patients than in partially edentulous patients. Therefore, the absence of cancellous bone seems to be higher in completely edentulous than in partially edentulous patients.

Keywords: Dental Implantation; Athrophy; Maxilla; Mandible; Prevalence.

\section{Introduction}

In completely and partially edentulous patients, rehabilitation using dental implants is a well documented treatment in various clinical situations. However, not all patients should be submitted to this type of rehabilitation, particularly because of the deficiency of bone tissue that allows implant placement. ${ }^{1}$ Despite this issue, it seems reasonable to state that it's possible to correct most of these bone deficiencies, thus broadening the range of patients eligible for implant-supported rehabilitation. For this purpose, surgical techniques that use donor sites that allow bone gain (i.e., autogenous grafts) or the use of bone substitutes (e.g., homogeneous, xenogeneic or synthetic grafts) are been used. ${ }^{2}$

Correction of bone defects should be carefully evaluated in relation to the characteristics of the remaining bone tissue. This can be achieved 
with the help of a classification system to organize and categorize the different types of defects, assisting the professional in the individualized planning of the case. One of these classifications proposed by Pelegrine et al., ${ }^{3}$ HAC (Horizontal Alveolar Change Classification), addresses horizontal bone defects involving the maxilla and/or mandible.

HAC classification presents four categories (i.e., HAC 1, 2, 3 and 4), and the examination of choice to enable such categorization is cone-beam computed tomography (CBCT). This examination represents a tool that is used very frequently in dentistry, and the classification system allows the categorization of the horizontal bone defect according to the presence or absence of cancellous bone tissue. Moreover, the classification system indicates the type of graft material that could be used for each case and is a predictor of results, according to information presented in Table.

According to HAC classification, in situations of horizontal bone loss that result in HAC 4 defects, there is a demand for autogenous bone grafting or the use of tissue engineering techniques ${ }^{3}$. By contrast, in all other situations (i.e., HAC 1, 2 and 3), there is no imperative need for vitalized grafts. Because the approach of a donor bed in autogenous grafting has been related to a greater potential for postoperative morbidity ${ }^{4}$ and with the current tendency for the selection of less invasive procedures, the determination of edentulous sites that allow reconstruction with another type of bone grafting material (i.e., homogeneous, xenogeneic or alloplastic grafts) is of great importance in daily clinical practice. In this scope, a study of the prevalence of different types of horizontal bone defects becomes of great importance to allow the presentation of the scenario found in both completely and partially edentulous individuals. Therefore, the aim of this study was to assess the prevalence of horizontal alveolar changes in partially and completely edentulous patients using cone-beam computed tomography.

\section{Methodology}

This study was designed as a retrospective examination of CBCT scans to assess the horizontal alveolar changes in partially and completely edentulous patients. In total, the 1516 CBCT scans of 1404 adult patients ( $\geq 18$ years) in the image database of Faculdade São Leopoldo Mandic, Instituto de Pesquisa São Leopoldo Mandic, were analyzed. A single and calibrated examiner (M. A. D.) analyzed all the images between August 2017 and

Table. Horizontal Alveolar Change (HAC) classification.

\begin{tabular}{|c|c|c|c|c|c|c|c|}
\hline Classification & $\begin{array}{l}\text { Amount of } \\
\text { alveolar } \\
\text { horizontal loss }\end{array}$ & $\begin{array}{l}\text { Surgical } \\
\text { approach } \\
\text { (stages) }\end{array}$ & $\begin{array}{l}\text { Presence of } \\
\text { cancellous } \\
\text { bone }\end{array}$ & $\begin{array}{c}\text { Imperative need of autogenous } \\
\text { graft or bone inductive } \\
\text { proteins/live cell transplant }\end{array}$ & $\begin{array}{c}\text { Material for } \\
\text { augmentation }\end{array}$ & $\begin{array}{l}\text { Maxilla } \\
\text { aspect on } \\
\text { CT }\end{array}$ & $\begin{array}{l}\text { Mandible } \\
\text { aspect on } \\
\text { CT }\end{array}$ \\
\hline $\mathrm{HACl}$ & Small & Single & Yes & No & No & & \\
\hline HAC2 & Small & Single & Yes & No & $\begin{array}{l}\text { Osseoconductive } \\
\text { biomatrial }\end{array}$ & & \\
\hline HAC3 & Moderate & Two & Yes & No & $\begin{array}{l}\text { Osseoconductive } \\
\text { biomatrial }\end{array}$ & & \\
\hline HAC4 & Large & Two & No & Yes & $\begin{array}{c}\text { Autogenous or } \\
\text { biomaterial with bone } \\
\text { inductive proteins/live } \\
\text { cell transplant }\end{array}$ & & \\
\hline
\end{tabular}

Source: Pelegrine et al. ${ }^{3}$ 
December 2018. This study was approved by the Ethics Committee of São Leopoldo Mandic Institute (Protocol number 88483218.5.0000.5374).

\section{Inclusion criteria}

Patients who needed either no bone augmentation or horizontal bone augmentation and who were evaluated by CT scans performed prior to the beginning of dental implant treatment were included. Only scans from adult patients ( $\geq 18$ years) were selected for this study.

\section{Non-inclusion criteria}

Any CBCT scan that showed signs of trauma, supernumerary teeth, crowding, previous apical surgery, and cysts and any images that presented with a lack of clarity or excessive scattering were excluded.

\section{Computed tomography analysis}

\section{Image device}

An i-CAT 3D (Kavo Dental GmbH, Biberach, Germany) CBCT unit equipped with a full $24.2 \mathrm{~cm}$ $\times 19.3 \mathrm{~cm}$ sensor capable of yielding a full height three-dimensional (3D) scan $(13 \mathrm{~cm} \times 16 \mathrm{~cm})$ in 4.8 seconds and a voxel size (slice thickness $=0.3 \mathrm{~mm}$ ) at $0.3 \times 0.3 \times 0.3 \mathrm{~mm}$ was used to capture, process, and store the reconstructed $3 \mathrm{D}$ data together with the original two-dimensional projection views. The tube voltage and current were fixed at $85 \mathrm{kV}$ and $7 \mathrm{~mA}$, as recommended by the manufacturer. Accuracy was limited to the inherent voxel size $(0.3 \mathrm{~mm})$ of the CBCT machine used in acquiring the scans.

\section{Image manipulation}

A sagittal view for each area was reconstructed and analyzed by a computer using i-CATVision (Kavo Dental GmbH, Biberach, Germany) 3D visualization and measurement software. Alveolar ridge thickness and the presence or absence of cancellous bone were evaluated. All analyses were performed by a single experienced examiner (MAD) and were confirmed by a second examiner (AAP) with a 15-day interval between both analyses.

\section{Image evaluation}

Images obtained in DICOM format with 96 dpi resolution and 14-bit grayscale and were converted and analyzed using Dental Slice software (Bioparts, Brasília, Brazil) (Figure 1). Assessment of the images was made in accordance with the horizontal alveolar change (HAC) classification, considering the worst scenario per jaw (i.e., the lowest area of available bone). As determined previously by Pelegrine et al., ${ }^{3}$ the following classification was based on four different situations:

a. HAC 1: slight bone resorption without bone reconstruction need due to the possibility of implant placement in an ideal position without grafting. There is the presence of cancellous bone between the cortical buccal and palatal/lingual bone plates and possibility of a single surgical approach with immediate implant placement.

b. HAC 2: slight bone resorption with a minor need for bone reconstruction that can be achieved using an osteoconductive biomaterial because of the presence of cancellous bone between the cortical buccal and palatal/ lingual bone plates. It also allows for a single surgical approach, with immediate implant placement.

c. HAC 3: moderate bone resorption, but still with remaining cancellous bone at the residual alveolar site, requiring only the use of osteoconductive biomaterial for reconstruction. However, because the required bone reconstruction is significant, in these situations, a two-stage surgical approach is usually needed: first, just the bone graft procedure and, a few months later, the implant.

d. HAC 4: severe bone resorption, with no remaining cancellous bone at the residual alveolar site, requiring the use of osteoconductive, osteoinductive, and osteogenic material (i.e., autogenous bone graft or bone tissue engineering with live cell transplantation or bone-inductive proteins). Because the required bone reconstruction is significant, a two-stage surgical approach is imperative. 

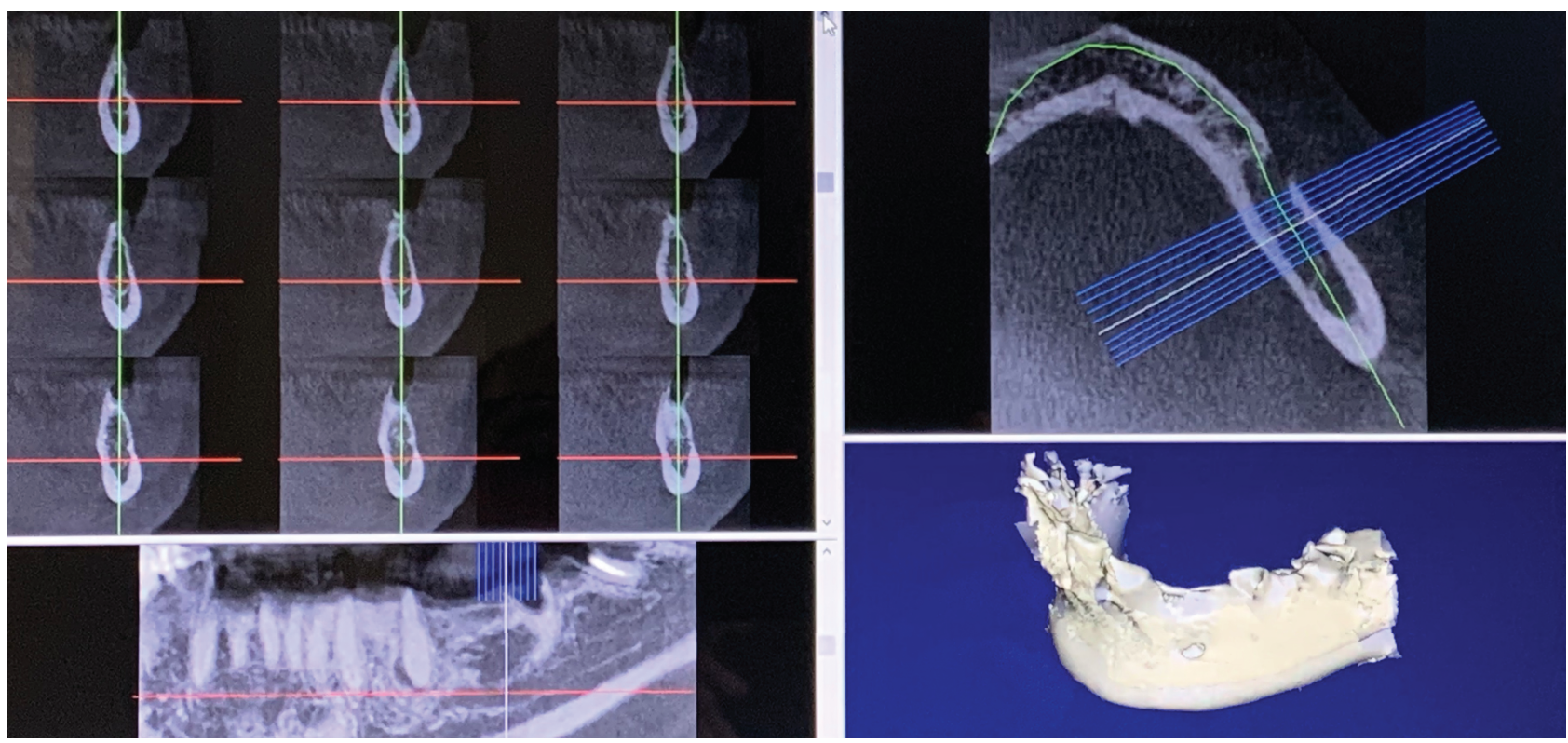

Figure 1. Screenshot of DentalSlice software.

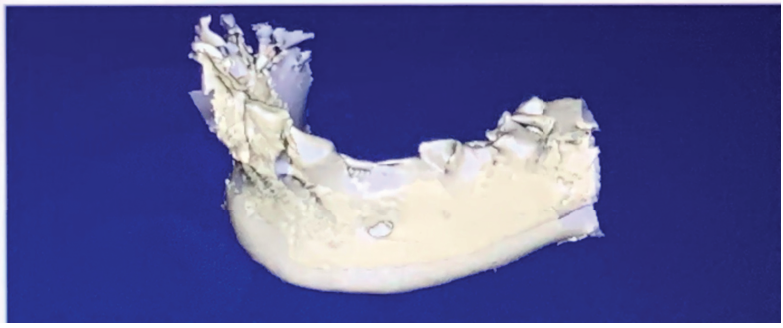

\section{Results}

\section{Descriptive statistics}

In total, 1516 CBCT scans from 1404 patients, 458 men and 946 women, with an age range from 18 to 75 years ( $56 \pm 10.4$ years), were analyzed. The analysis of 1048 scans from partially edentulous patients presented a distribution of $63.55 \%, 22.14 \%$, $11.55 \%$ and $2.6 \%$ in HAC 1, HAC 2 , HAC 3 and HAC 4 , respectively.

Analysis of 468 scans from completely edentulous patient presented a distribution of $19.87 \%, 28.63 \%$, $41.67 \%$ and $9.83 \%$ in HAC 1, HAC 2 , HAC 3 and HAC 4, respectively.

Figure 2 shows the results for both partially and completely edentulous patients.

\section{Discussion}

The purpose of this 2-year retrospective study was to investigate the pre-surgical morphology analysis of the alveolar ridge of patients who would undergo bone augmentation surgeries. This issue is of major importance due to the need for an adequate treatment plan for bone graft procedures. Thus, knowledge of the prevalence of different types of bone defects certainly would assist the clinicians to understand the clinical scenario of bone defects in both partially and completely edentulous patients. Moreover, because appositional bone graft techniques are related to high rates of complications, ${ }^{5}$ it is important to categorize the defects in order of complexity. However, because the loss of bone thickness precedes the loss of height ${ }^{6,}$ which explains why appositional approaches aimed at horizontal augmentation are the most prevalent, the present study focused on the determination of the prevalence of different types of horizontal bone defects. In this study, a total of 1516 CBCT scans from 1404 patients were evaluated. The number of CBCT scans was higher than the number of patients because some patients had edentulous sites in different jaws (i.e. maxilla and mandible).

In a previous study, our group developed a classification of horizontal alveolar changes based, specifically, on the presence or absence of cancellous bone. ${ }^{3}$ This retrospective study showed that, in sites where the cancellous bone is absent, bone reconstruction is only predictable using a vitalized bone graft (e.g., autografts). On the other hand, this study showed that horizontal bone augmentation using bone substitutes (i.e., allograft, alloplastic and xenograft) is predictable in situations where 


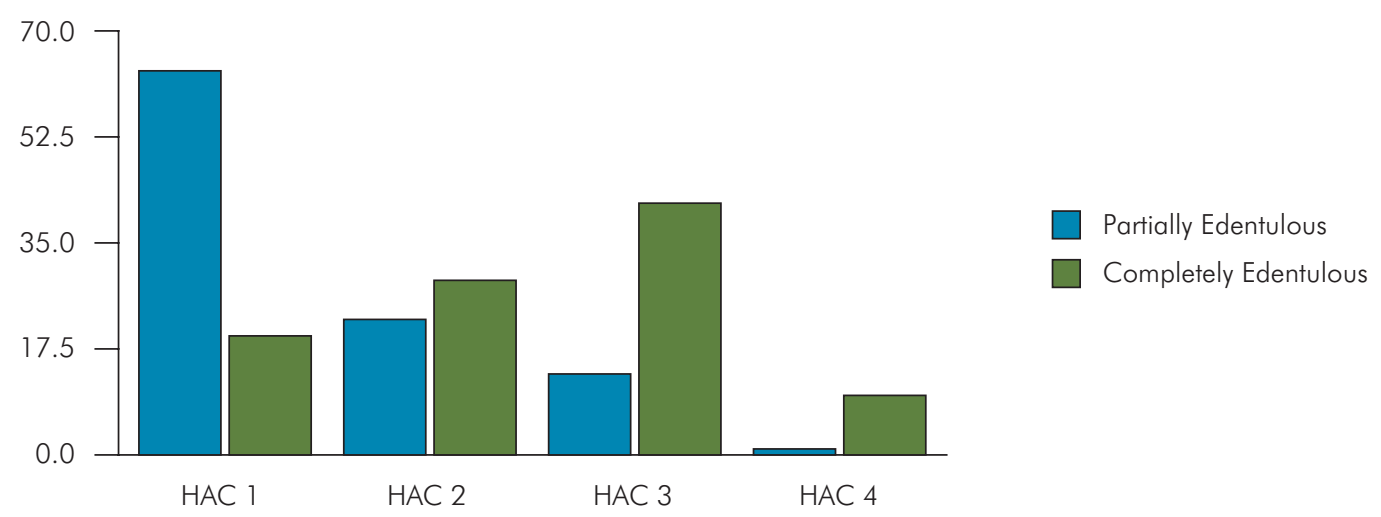

Figure 2. Prevalence of partially and completely edentulous patients for HAC 1, HAC 2, HAC 3 and HAC 4.

cancellous bone is present between the buccal and lingual/palatal cortical bone plates. Therefore, this previously published classification contributes to the decision-making process concerning bone augmentation therapy. These findings encouraged our group to develop the HAC (Horizontal Alveolar Changes) Classification (Table) in a previous study and, in the present study, to establish the prevalence of each HAC subtype for partially and completely edentulous patients.

In the present study, it was showed that the prevalence rates of HAC 1 and 2 for partially edentulous patients were much higher when compared to completely edentulous patients. Therefore, regarding HAC 1 and 2, because there is no need to perform implant placement in a second surgical stage, it is possible to verify that a single-stage approach could be used for most of the partially edentulous patients because HAC 1 and 2 represent $85.69 \%$. On the other hand, for completely edentulous patients, HAC 1 and 2 are present in $48.5 \%$ of cases. Thus, although HAC 3 demands in some situations a single- or two-stage approach, it can be speculated that the need for a two-stage approach would be more frequent in completely edentulous than in partially edentulous patients. This finding can also be verified by analyzing the prevalence of HAC 3 and HAC 4 . Considering HAC 3 and HAC 4 together, the prevalence in partially edentulous patients was $14.31 \%$ and that in completely edentulous was $51.50 \%$. Because HAC 3 and HAC 4 are unique situations that can demand a two-stage surgical approach, the regenerative treatment of completely edentulous patients could present more morbidity. Moreover, similar to HAC 4, in which there is an imperative need for autogenous bone graft (or tissue engineering techniques), completely edentulous patients could be related to a higher indication of donor area bone collection, due to the prevalence of $9.83 \%$ of HAC 4 in completely edentulous versus $0.95 \%$ in partially edentulous patients. As the approach of the donor area is related to more morbidity than the recipient site ${ }^{4}$ the morbidity of the recipient bed is more prevalent in completely edentulous patients. Moreover, the findings of the present study, when analyzed together with the findings of the previous study of our group ${ }^{3}$, might permit us to infer that the need for a vitalized graft, such as autogenous bone, seems to be more necessary in a higher number of completely edentulous patients than in partially edentulous patients, and the opposite can be stated concerning the need for any kind of bone augmentation.

When analyzing the results for HAC 1 prevalence in isolation, a huge difference was observed between partially and completely edentulous patients $(63.55 \%$ and 19.87, respectively). Because HAC 1 indicates "no need for bone reconstruction due to the possibility of implant placement in an ideal position without grafting", in partially edentulous patients, the need for any type of bone augmentation seems to be less necessary than that in completely edentulous patients. It does not means that, in HAC 1, slight bone augmentation or even a soft tissue graft cannot be performed for aesthetics purposes in HAC 1 
situations, especially in anterior sites in patients with a gummy smile. In this regard, even in situations of fresh sockets with no bone loss, a technique that uses bone grafts inside and over the external surface of the facial socket could be used for aesthetics purposes. ${ }^{7}$ Regarding this subject, Masaki et al. ${ }^{8}$ stated that, to obtain stable and long-term esthetics, it is necessary to combine soft-tissue grafts in addition to hard tissue augmentation.

In the present study, the prevalence differences observed between partially and completely edentulous patients could be explained, mainly, by the presence of the remaining teeth around the bone defects in partially edentulous patients. However, other circumstances such as the more frequent use of a removable prosthesis by completely edentulous patients should be considered. The complete preservation of alveolar bone is just possible by maintaining the root inside the socket because, although alveolar ridge preservation procedures are effective in reducing postextraction alveolar bone resorption, these procedures do not completely prevent postextraction hard tissue dimensional changes. ${ }^{9}$ The extraction of a tooth will result in some level of bone loss and, in sites with a thin buccal bone plate, approximately $35 \%$ of thickness loss is expected 6 months after extraction. ${ }^{10,11}$ The presence of adjacent teeth, by maintaining the bone structure around them, minimizes the horizontal bone loss of adjacent edentulous areas. Thus, based on HAC Classification, as the presence of cancellous bone allows the usage of bone substitute biomaterials, the results of the present prevalence study show that these biomaterials could be used more to treat partially than completely edentulous patients (and the opposite can be stated concerning the use of autografts). This statement is, mainly, based on the knowledge that the cortical lamellar bone does not have a high level of vitality ${ }^{12}$ and that the cancellous compartment has high vitality and a huge osteogenic potential, mainly due to the endosteum and bone marrow. ${ }^{13}$

Different classifications of ridge defects have been published, such as the classifications of Seibert, ${ }^{14}$ Allen et al., ${ }^{15}$ Lekholm and Zarb, ${ }^{16}$ Misch and Judy ${ }^{17}$ and, more recently, Wang and Al-Shammari ${ }^{18}$ and Park et al. ${ }^{19}$ However, these classifications do not correlate between the defect characteristic and the possibility of using bone substitute biomaterials or indicate the imperative use of vitalized grafts. Nevertheless, despite the importance of HAC Classification published in $2018^{3}$ and importance of the present prevalent study, it is important to recognize that both studies are based in retrospective analysis and, therefore, the accomplishment of future investigations with a prospective design is mandatory. Moreover, a dataset of only one university was used, which is a limitation of this study.

\section{Conclusions}

Based on this prevalence study, the absence of cancellous bone is higher in completely edentulous patients than that in partially edentulous patients.

\section{Acknowledgments}

The authors would like to thank CAPES for the financial support (\#001).

\section{References}

1. Sanz-Sánchez I, Carrillo de Albornoz A, Figuero E, Schwarz F, Jung R, Sanz M, et al. Effects of lateral bone augmentation procedures on peri-implant health or disease: A systematic review and meta-analysis. Clin Oral Implants Res. 2018 Mar;29(15 Suppl 15):18-31. https://doi.org/10.1111/clr.13126

2. Zheng X, Teng M, Zhou F, Ye J, Li G, Mo A. Influence of maxillary sinus width on transcrestal sinus augmentation outcomes: radiographic evaluation based on cone beam CT. Clin Implant Dent Relat Res. 2016 Apr;18(2):292-300. https://doi.org/10.1111/cid.12298

3. Pelegrine AA, Romito G, Villar CC, Macedo LG, Teixeira ML, Aloise AC, et al. Horizontal Bone Reconstruction on sites with different amounts of native bone: a retrospective study. Braz Oral Res. 2018;32(0):e21. https://doi.org/10.1590/1807-3107bor-2018.vol32.0021 
Dias MA, Romito G, Villar CC, Aspata VM, Teixeira ML, Aloise AC, et al.

4. Chappuis V, Cavusoglu Y, Buser D, Arx T. Lateral ridge augmentation using autogenous block grafts and guided bone regeneration: a 10 -year prospective case series study. Clin Implant Dent Relat Res. 2017 Feb;19(1):85-96. https://doi.org/10.1111/cid.12438

5. Jepsen S, Schwarz F, Cordaro L, Derks J, Hämmerle CH, Heitz-Mayfield LJ, et al. Regeneration of alveolar ridge defects. Consensus report of group 4 of the 15th European Workshop on Periodontology on Bone Regeneration. J Clin Periodontol. 2019 Jun;46(21 Suppl 21):277-86. https://doi.org/10.1111/icpe.13121

6. Jensen SS, Terheyden H. Bone augmentation procedures in localized defects in the alveolar ridge: clinical results with different bone grafts and bone-substitute materials. Int J Oral Maxillofac Implants. 2009;24 Suppl:218-36.

7. Simon BI, Von Hagen S, Deasy MJ, Faldu M, Resnansky D. Changes in alveolar bone height and width following ridge augmentation using bone graft and membranes. J Periodontol. 2000 Nov;71(11):1774-91. https://doi.org/10.1902/jop.2000.71.11.1774

8. Masaki C, Nakamoto T, Mukaibo T, Kondo Y, Hosokawa R. Strategies for alveolar ridge reconstruction and preservation for implant therapy. J Prosthodont Res. 2015 Oct;59(4):220-8. https://doi.org/10.1016/i.jpor.2015.04.005

9. Bassir SH, Alhareky M, Wangsrimongkol B, Jia Y, Karimbux N. systematic review and meta-analysis of hard tissue outcomes of alveolar ridge preservation. Int J Oral Maxillofac Implants. 2018 Sep/Oct;33(5):979-94. https://doi.org/10.11607/jomi.6399

10. Araújo MG, Lindhe J. Dimensional ridge alterations following tooth extraction. An experimental study in the dog. J Clin Periodontol. 2005 Feb;32(2):212-8. https://doi.org/10.1111/j.1600-051X.2005.00642.x

11. Pelegrine AA, Costa CE, Correa ME, Marques Junior JF. Clinical and histomorphometric evaluation of extraction sockets treated with an autologous bone marrow graft. Clin Oral Implants Res. 2010 May;21(5):535-42. https://doi.org/10.1111/j.1600-0501.2009.01891.x

12. Lindhe J, Lang N. Clinical periodontology and implant dentistry. 6th ed. Chichester: Wiley-Blackwell; 2015.

13. Gray JC, Elves MW. Early osteogenesis in compact bone isografts: a quantitative study of contributions of the different graft cells. Calcif Tissue Int. 1979;29(3):225-37. https://doi.org/10.1007/BF02408085

14. Seibert JS. Reconstruction of deformed, partially edentulous ridges, using full thickness onlay grafts. Part I. Technique and wound healing. Compend Contin Educ Dent. 1983 Sep-Oct;4(5):437-53.

15. Allen EP, Gainza CS, Farthing GG, Newbold DA. Improved technique for localized ridge augmentation. A report of 21 cases. J Periodontol. 1985 Apr;56(4):195-9. https://doi.org/10.1902/jop.1985.56.4.195

16. Lekholm U, Zarb G. Patient selection and preparation. In: Brånemark PI, editor. Tissue-integrated prostheses: osseointegration in clinical dentistry. Chicago: Quintessence; 1985. pp. 199-209.

17. Misch CE, Judy KW. Classification of partially edentulous arches for implant dentistry. Int J Oral Implantol. 1987;4(2):7-13.

18. Wang HL, Al-Shammari K. HVC ridge deficiency classification: a therapeutically oriented classification. Int J Periodontics Restorative Dent. 2002 Aug;22(4):335-43.

19. Park SH, Brooks SL, Oh TJ, Wang HL. Effect of ridge morphology on guided bone regeneration outcome: conventional tomographic study. J Periodontol. 2009 Aug;80(8):1231-6. https://doi.org/10.1902/jop.2009.090090 